\title{
Cyclophilin D modulates cell death transition from early apoptosis to programmed necrosis induced by honokiol
}

\author{
WEI TIAN ${ }^{1,2^{*}}$, DONG XU $^{1 *}$, WEIDONG HAN ${ }^{3}$, HAIFEI HE $^{1}$, HONGKE CAI $^{1}$, HAILONG CHEN $^{1,2}$, \\ MEIQI ZHOU ${ }^{1}$, JIANI CHEN ${ }^{1}$ and YONG-CHUAN DENG ${ }^{1}$ \\ ${ }^{1}$ Department of Surgical Oncology, ${ }^{2}$ Cancer Institute (The Key Laboratory of Cancer Prevention and Intervention, \\ China National Ministry of Education), The Second Affiliated Hospital, School of Medicine, \\ Zhejiang University, Hangzhou 310009, P.R. China; ${ }^{3}$ Division of Stem Cell and Leukemia Research, \\ City of Hope National Medical Center, City of Hope, Duarte, CA 91010, USA
}

Received December 16, 2012; Accepted February 15, 2013

DOI: $10.3892 /$ ijo.2013.1863

\begin{abstract}
Honokiol is a pharmacologically active small molecule with multifunctional antitumor effects. Although plenty of literature is available on honokiol-triggered apoptosis and programmed necrosis, few studies have investigated the potential existence of death mode transition from apoptosis to programmed necrosis. In the current study, we demonstrated that the necrotic cell population (PI-positive) gradually increased and the early-stage apoptotic cell population (PI-negative and AV-positive) decreased in a dose- and time-dependent manner following honokiol treatment. Furthermore, we demonstrated that these PI-positive cells were under necrotic cell death, since no late-apoptosis characteristics including conspicuous chromatin condensation or DNA ladder patterns were detected. These results demonstrated that cells suffered death mode transition from early-stage apoptosis to programmed necrosis with the increase of honokiol dose or treatment time. The protein expression of RIP3 markedly increased in parallel with HNK-triggered death mode transition, while the expression of RIP1 decreased. Cyclophilin D expression increased during cell death mode transition, and inhibition of cyclophilin $\mathrm{D}$ by cyclosporin A clearly blocked HNK-triggered programmed necrosis. These data indicated that honokiol-induced programmed necrosis and death mode transition are potentially RIP3-dependent, cyclophilin D-regulated. Further results
\end{abstract}

Correspondence to: Professor Yong-Chuan Deng, Department of Surgical Oncology, The Second Affiliated Hospital, School of Medicine, Zhejiang University, 88 Jiefang Road, Hangzhou 310009, P.R. China

E-mail: dengyongchuanzju@gmail.com

*Contributed equally

Key words: honokiol, apoptosis, programmed necrosis, receptorinteracting protein kinases 1, receptor-interacting protein kinases 3, cyclophilin D showed that blocked cyclophilin D by cyclosporin A inhibited HNK-induced necrosis, but did not affect HNK-induced RIP3 overexpression. This indicated that cyclophilin D was a potential modulator at downstream of RIP3. In conclusion, honokiol triggers a potential RIP3-dependent cell death mode transition from early-stage apoptosis to programmed necrosis, which is highly regulated by cyclophilin D.

\section{Introduction}

Programmed cell death is a crucial cellular process under both physiological and pathological conditions. Emerging evidence provides deep insights into the molecular pathways regulating and executing programmed cell death. Basing on a range of measurable biochemical features and morphological criteria, programmed cell death is further sub-classified as extrinsic apoptosis, caspase-dependent or -independent intrinsic apoptosis, programmed necrosis, autophagic cell death and others (1). Resembling apoptosis, necrosis can also proceed under a regulated way. This regulated necrosis is frequently termed as 'programmed necrosis', which is highly regulated by receptor-interacting protein kinases 1 (RIP1) and 3 (RIP3) (2). In classical programmed necrosis (or 'necroptosis') triggered by TNF, assembly of RIP1and RIP3 forming a necrotic complex (termed as 'necrosome') is critical in initiation of programmed necrotic process. However, current studies on programmed necrosis triggered by other stimuli demonstrate programmed necrosis can also be initiated in a RIP1-independent but RIP3-dependent manner. Accumulating evidence indicates RIP3 is indispensable for programmed necrosis and participates in constitution of all demonstrated necrotic complex triggered by various stimuli, whereas RIP1 participates in certain stimuli induced programmed necrosis (3). Apoptotic and programmed necrotic signaling pathways share some vital corporate molecules. Consequently, it is comprehensible that certain chemicals trigger different cell death modes in dose-dependent manner (autophagy or apoptosis after lower-dose exposure and necrosis at higher-dose exposure).

Honokiol (HNK) is a pharmacologically active small molecule with multifunctional antitumor effects (4). Apoptosis is the 
best-demonstrated mechanism through which HNK accomplish its antitumor effects in various cancer cell lines. HNK induces apoptosis through both death receptor (extrinsic) pathway (5-8) and mitochondrial (intrinsic) pathway $(9,10)$. Besides apoptosis, we previously reported HNK induced programmed necrotic cell death in HL60, MCF-7 and HEK293 cells at certain doses through mitochondrial permeability transition pore (11). This programmed necrosis is highly-regulated by cyclophilin D (CypD) (11). Although emerging evidence concerns programmed cell death triggered by HNK, little attention has been paid to the potential existence of death modes transition from apoptosis to programmed necrosis and the possible mechanism. We investigated honokiol-induced cell death mode transition, and potential regulation mechanism in the current study.

\section{Materials and methods}

Reagents and chemicals. Honokiol was purchased from the National Institute for the Control of Pharmaceutical and Biological Products (Beijing, China) with $>99 \%$ purity. Honokiol power was dissolved in DMSO at $20 \mathrm{mg} / \mathrm{ml}(75 \mathrm{mM})$. z-VAD-fmk was from Beyotime Institute of Biotechnology (Shanghai, China). PrimeScript ${ }^{\circledR}$ RT reagent Kit (Perfect Real-Time) and SYBR ${ }^{\circledR}$ Premix Ex Taq ${ }^{\mathrm{TM}}$ II (Tli RNase H Plus) were purchased from Takara Biotechnology Co. Ltd (Dalian, China). DNA Ladder Detection Kit was from KeyGEN Biotech (Nanjing, China). M-PER ${ }^{\circledR}$ Mammalian Protein Extraction Reagent was from Thermo Scientific (Pierce Biotechnology, Rockford, IL, USA). RIP1 antibody and Annexin V-FITC/PI kit were from R\&D Systems (Minneapolis, MN, USA). RIP3 and Bcl-2 antibodies were purchased from Epitomics (Burlingame, CA, USA), PTEN, Bcl-xl and GAPDH antibodies were from Cell Signaling Technology (Danvers, MA, USA).

Cell culture. Human breast carcinoma cell lines were obtained from Cancer Institution of Zhejiang University (Zhejiang, China). MCF-7 was maintained in RPMI-1640 medium. MDA-MB-231 was cultured in L-15. Bcap-37, T47D and SKBR-3 were maintained in DMEM. All media were supplemented with $10 \%$ FBS. The multidrug resistant human breast carcinoma cell line MCF-7/ADR and Bcap-37/ADR was developed as reported previously (12) and maintained in RPMI-1640 (supplemented with 10\% FBS) with 1 and $0.5 \mu \mathrm{g} / \mathrm{ml}$ doxorubicin.

Cell toxicity assay. Breast cancer cells of cultured cell lines were seeded in 96-well culture plates at density of $6,000-8,000$ cells/well and cultured for $24 \mathrm{~h}$ pretreatment. Then, cells were incubated with drug-free medium, honokiol of different concentrations for different time durations. Cell toxicity assays were preformed using MTT method as described previously (12).

Flow cytometric analysis for cell apoptosis and necrosis.MCF-7 cells were cultured in 6-well culture plates at $8-10 \times 10^{5} /$ well in $2 \mathrm{ml}$ medium for $24 \mathrm{~h}$. Cells were treated with $0.1 \%$ DMSO (vehicle control) and honokiol at different concentrations (liquid volume: $1.5 \mathrm{ml} /$ well) for different time durations. After treatment, cells were stained with Annexin V-FITC/PI and assayed by flow cytometry as previously described (12).
Assessment of chromatin condensation using Hoechst 33342 staining by confocal imaging. Cells were seeded and treated as in flow cytometric analysis for cell apoptosis and necrosis. Cells were fixed in $4 \%$ phosphate-buffered paraformaldehyde for $10 \mathrm{~min}$ and were washed twice with PBS subsequently. Then cells were incubated with $10 \mu \mathrm{g} / \mathrm{ml}$ Hoechst 33342 for $10 \mathrm{~min}$ in dark at room temperature. Nuclei stains of Hoechst 33342 were examined under a confocal microscope (Leica TCS SP5). Hoechst reagent was taken up by the cell nuclei, and apoptotic cells exhibited a bright blue fluorescence.

DNA ladder detection. Cells were seeded and treated as in flow cytometric analysis for cell apoptosis and necrosis. After treatment, cells were collected and washed twice with chilled PBS. DNA gel electrophoresis was done after DNA extraction according to the manufacturer's instructions of DNA Ladder Detection Kit. HL60 cells treated with $20 \mu \mathrm{g} / \mathrm{ml} \mathrm{VP-16}$ for $6 \mathrm{~h}$ were used as positive control.

Real-time RT-PCR quantification of $m R N A$. Cells were seeded and treated as in flow cytometric analysis for cell apoptosis and necrosis. Total RNA was extracted using TRIzol reagent (Invitrogen, Carlsbad, CA, USA). Concentration and quality of RNA were measured by Nanodrop 1000 spectrophotometer (Thermo Scientific). Total RNA were reverse transcribed using PrimeScript ${ }^{\circledR}$ RT reagent Kit (Takara Biotechnology Co. Ltd). Subsequently, real-time PCR reactions were performed using SYBR $^{\circledR}$ Premix Ex Taq ${ }^{\mathrm{TM}}$ II (Tli RNaseH Plus) Kit (Takara Biotechnology Co. Ltd) on Stepone Plus System (Applied Biosystems, Foster City, CA, USA). Detailed primer sequences are summarized in Table I. PCR reaction conditions were: $95^{\circ} \mathrm{C}$ for $30 \mathrm{sec}, 40$ cycles with $95^{\circ} \mathrm{C}$ for $5 \mathrm{sec}$ and $60^{\circ} \mathrm{C}$ for $30 \mathrm{sec}$. $\beta$-actin was applied as internal reference for normalization. All the above operation procedures were performed according to the manufacturer's protocols. $\Delta \Delta \mathrm{Ct}$ method was introduced to determine the relative mRNA expression level.

Western blot analysis. Cells were treated and harvested as in flow cytometric analysis for cell apoptosis and necrosis, protein was extracted using M-PER ${ }^{\circledR}$ Mammalian Protein Extraction Reagent. Protein concentrations were determined with BCA method. A total of $20 \mu \mathrm{g}$ of each sample was loaded on the gel and procedure of electrophoresis and western blot analysis were performed as previously described (11). After PVDF membranes were ready for antibody staining, they were incubated with appropriate primary antibodies at $4^{\circ} \mathrm{C}$ overnight and HRP-conjugated second antibodies at room temperature for $1 \mathrm{~h}$ in sequence. ECL detection kit was introduced for signal development. Images were acquired using chemiluminesence. Jurkat cells were used as positive control in analysis RIP3 protein expression.

Statistical analysis. All the experiments were done in triplicate, and similar results were obtained in three different experimental setups. The data represent means \pm standard deviation. One-way analysis of variance (ANOVA) was used for evaluations of time- and dose-response curves. Student's $\mathrm{t}$-test was used in single group comparisons. $\mathrm{P}<0.05$ was considered statistically significant. 
Table I. Primer used for quantitative real-time PCR analyses of gene expression.

\begin{tabular}{|c|c|}
\hline $\begin{array}{l}\text { Targeted } \\
\text { gene }\end{array}$ & $\begin{array}{l}\text { Primer sequences } \\
\qquad\left(5^{\prime} \text { to } 3^{\prime}\right)\end{array}$ \\
\hline CypD & $\begin{array}{l}\text { Forward:AACCTGCTAAATTGTGCGTTATTG } \\
\text { Reverse: TAATAGCCATCTCCCAGTTCTG }\end{array}$ \\
\hline$\beta$-actin & $\begin{array}{l}\text { Forward:TTCCAGCCTTCCTTCCTGGG } \\
\text { Reverse: TTGCGCTCAGGAGGAGCAAT }\end{array}$ \\
\hline
\end{tabular}

Table II. The effects of HNK on breast cancer cell viability.

\begin{tabular}{lc}
\hline Cell line & $\mathrm{IC}_{50}(\mu \mathrm{g} / \mathrm{ml})$ \\
\hline MDA-MB-231 & 19.708 \\
SKBR-3 & 20.712 \\
T47D & 18.670 \\
Bcap-37 & 18.389 \\
MCF-7 & 21.940 \\
Bcap-37/ADR & 21.037 \\
MCF-7/ADR & 19.381 \\
\hline
\end{tabular}

MTT assay was employed to detect the cell viability. Each cell line was treated with various concentrations (range from 0.1 to $40 \mu \mathrm{g} / \mathrm{ml}$ ) of HNK for $24 \mathrm{~h}$, respectively. Data are expressed as means from three experiments.

\section{Results}

Cytotoxic effect of HNK on breast cancer cell lines. Our data revealed that HNK repressed cell viability of all tested breast cancer cell lines (MCF-7, MDA-MB-231, Bcap-37, T47D, SKBR-3, MCF-7/ADR and Bcap-37/ADR) after 24-h treatment with $\mathrm{IC}_{50}$ ranged from 18.389 to $21.940 \mu \mathrm{g} / \mathrm{ml}$ (Table II). HNK showed parallel cytotoxical effect on multidrug resistant cells and their corresponding sensitive cells (Table II). Further, we demonstrated that HNK had time- and dose-dependent cytotoxic effects on MCF-7 cells (Fig. 1).

HNK induces cell death mode transition in a time- and dosedependent manner. A range of chemicals trigger different cell death modes in a dose-dependent manner. Frequently, lower-dose exposure induces autophagy or apoptosis, whereas higher-dose induces necrosis (13). Our group previously reported that $\mathrm{HNK}$ at a concentration of $40 \mu \mathrm{g} / \mathrm{ml}$ triggered programmed necrosis in MCF-7 cells (11). Accordingly, we hypothesized HNK may trigger apoptosis to programmed necrosis transition in a time- and dose-dependent manner.

Cell death modes triggered by $\mathrm{HNK}$ at a fixed concentration $(40 \mu \mathrm{g} / \mathrm{ml})$ of different exposure durations were characterized using Hoechst 33342 staining, DNA laddering and flow cytometric analysis of Annexin V-FITC/PI staining. MCF-7 cells were incubated with $40 \mu \mathrm{g} / \mathrm{ml} \mathrm{HNK}$ for $30 \mathrm{~min}, 1$ and $6 \mathrm{~h}$, respectively, and then labeled with Annexin V-FITC (AV) and PI (Fig. 2). Even for the shortest incubating time (30 min), cell viability was significantly reduced by $40 \mu \mathrm{g} / \mathrm{ml} \mathrm{HNK}(\mathrm{P}<0.001)$

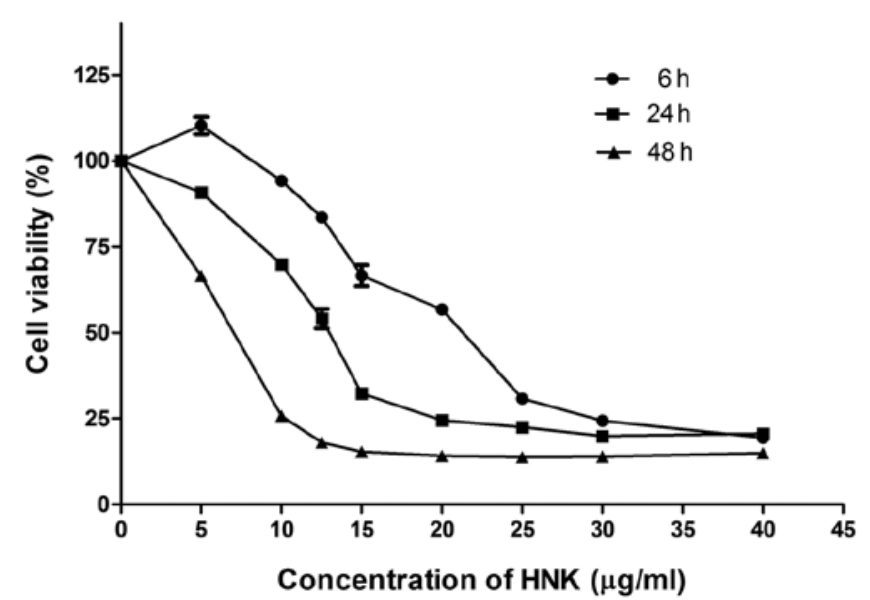

Figure 1. Cytotoxicity of honokiol in MCF-7 cells. After treatment with honokiol in dose-gradients for 6,24 and $48 \mathrm{~h}$, cell viability was analyzed by MTT assays. HNK manifested time- and dose-dependent cytotoxicity in MCF-7 cells. Results are representative of three independent experiments. The values shown are the mean \pm SD.

(Fig. 2A and C). Cell death was accelerated with the extension of incubating time (Fig. 2A and C). Necrotic cell death $\left(\mathrm{PI}^{+}\right)$ triggered by $40 \mu \mathrm{g} / \mathrm{ml}$ HNK increased $(\mathrm{P}<0.001)$ with the extension of incubating time, whereas early apoptotic cell death (AV staining positive and PI negative) manifested contrary tendency (Fig. 2C and D). Internucleosomal DNA fragmentation is one of the hallmarks of apoptosis at later stage (or degradation phase), which are simply detectable as a ladder pattern in electrophoresis of isolated DNA. Nuclear chromatin condensation and apoptotic bodies are both morphological characteristic manifestations of apoptosis and are detectable using nuclei staining by Hoechst 33342 . No obvious ladder pattern was observed in any of the treatment groups $(40 \mu \mathrm{g} / \mathrm{ml} \mathrm{HNK}$ incubation for $30 \mathrm{~min}, 1$, 2, 4 and 6 h, respectively) (Fig. 3A). Confocal imaging of Hoechst 33342-stained nuclei revealed no remarkable chromatin condensation or apoptotic bodies in any of the treatment groups, but anomalous diffuse staining were detected in groups with longer treatment durations (4 and 6 h) (Fig. 3B). Both DNA ladder and Hoechst 33342 staining assays demonstrated later-stage apoptosis were not the predominant cell death mode of $40 \mu \mathrm{g} / \mathrm{ml}$ HNK triggered cell death. Taken together, $40 \mu \mathrm{g} / \mathrm{ml} \mathrm{HNK}$ triggered a cell death mode transition from early-stage apoptosis to programmed necrosis in a time-dependent manner.

Death modes triggered by different concentrations $(20,25$, 30 and $40 \mu \mathrm{g} / \mathrm{ml}$ ) of HNK for $6 \mathrm{~h}$ were further analyzed. Cell fraction of early-stage apoptosis decreased, fraction of necrotic cell death conversely increased $(\mathrm{P}<0.001)$ with the extension of doses (Fig. 2B-D), which demonstrated similar tendency to that of time-dependent manner. However, no obvious DNA ladders or apoptotic bodies were detected using DNA laddering or Hoechst 33342-staining in any of the treatment groups (Fig. 3C and D). Such results also demonstrated HNK triggered cell death mode transition from early-stage apoptosis to programmed necrosis in a dose-dependent manner.

Collectively, these experimental results support the original hypothesis that HNK triggered cell death mode tran- 
A

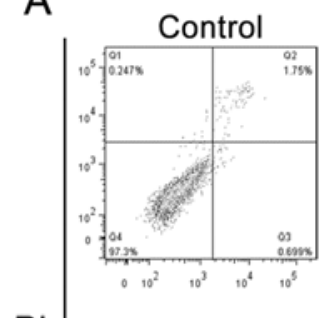

PI

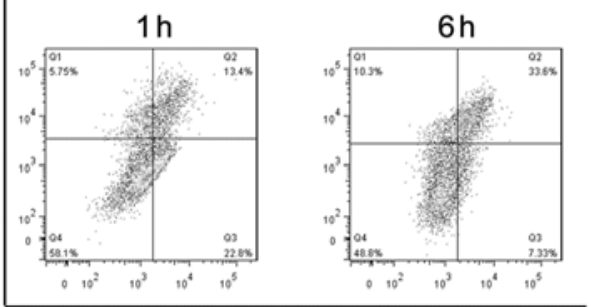

Annexin V-FITC

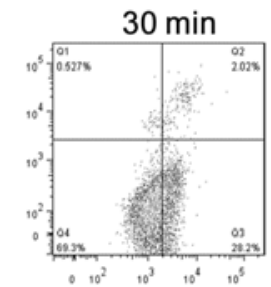

B

$\mathrm{Pl}$
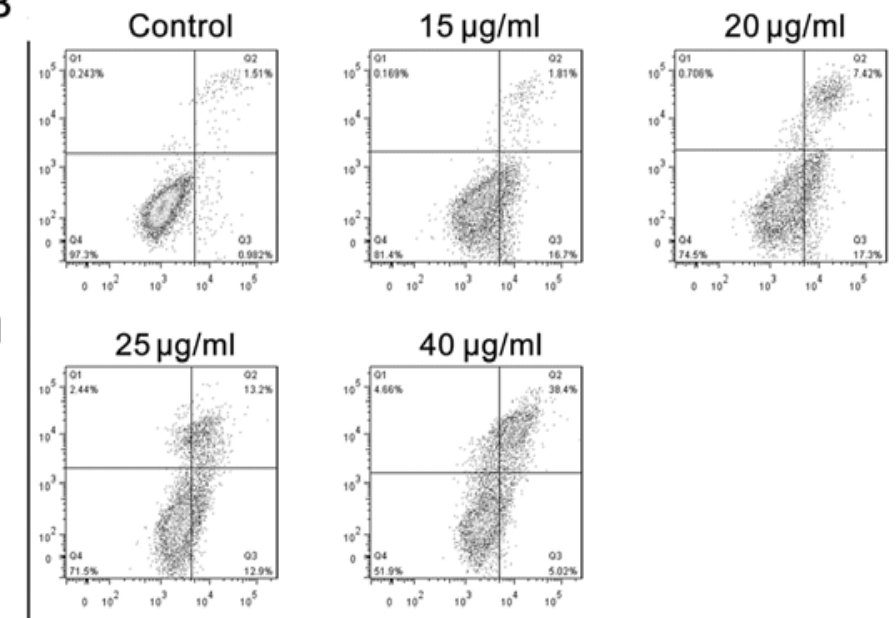

Annexin V-FITC
C

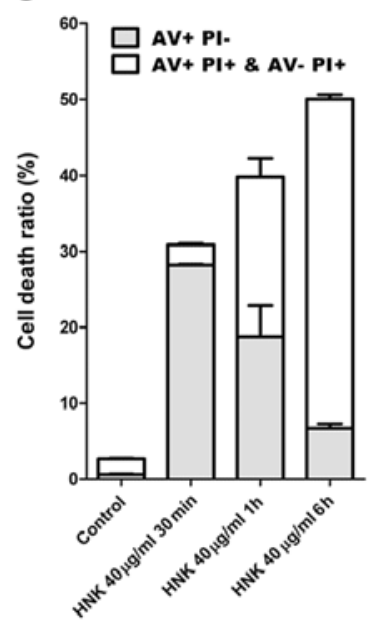

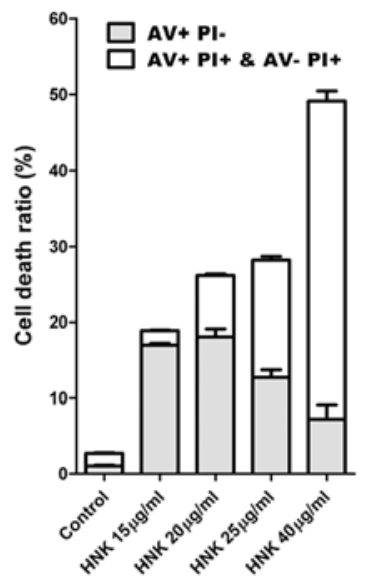

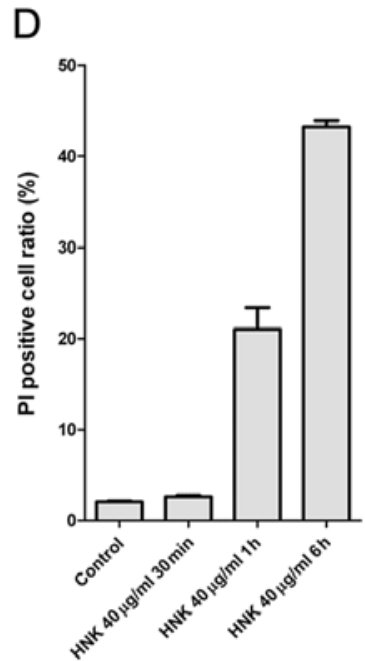

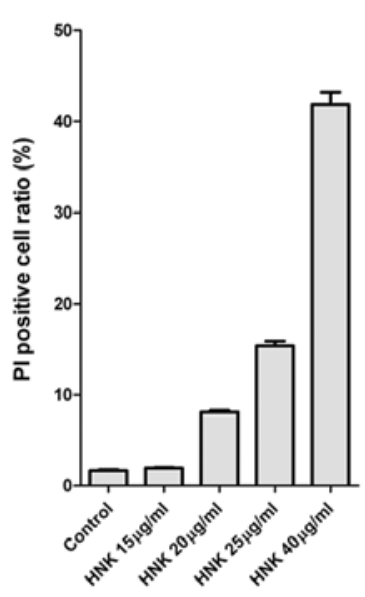

Figure 2. Honokiol triggers programmed cell death switching from apoptosis to programmed necrosis in a dose- and time-dependent manner. After treatment with dose-gradients or time-gradients HNK cells were labeled with Annexin V-FITC (AV) and PI, and then recorded by flow cytometric analysis. Flow cytometric analysis of cells after treating with (A) time-gradients or (B) dose-gradients of HNK. (C) Proportion of early-stage apoptosis (AV ${ }^{+} \mathrm{PI}^{-}$) decreased and that of necrosis $\left(\mathrm{PI}^{+}\right)$increased with extension of treatment time (from $30 \mathrm{~min}$ to $6 \mathrm{~h}$ ) at a fixed dose of $\mathrm{HNK}(40 \mu \mathrm{g} / \mathrm{ml})$ or with extension of $\mathrm{HNK}$ doses at a fixed treatment time in MCF-7 cells. (D) Necrotic cell death apparently increased after treatment with time-gradients $(\mathrm{P}<0.001)$ or dose-gradients $(\mathrm{P}<0.001)$ of $\mathrm{HNK}$. One-way analysis of variance (ANOVA) was used for evaluation of time- and dose-response curves. Results are representative of three independent experiments. The values shown are the mean \pm SD.

sition from apoptosis to programmed necrosis in a time- and dose-dependent manner.

Cyclophilin D modulates HNK-induced apoptosis to programmed necrotic cell death transition. Cyclophilin D $(\mathrm{CypD})$ is a vital protein involved in mitochondrial permeability transition (mPT) and critical regulator in HNK-induced programmed necrotic cell death (11). Recent reports demonstrated cyclophilin D-dependent mPT regulates some necrotic but not apoptotic cell death (14), and comports as apoptotic repressor $(15,16)$. In consequence, we explored whether HNK-induced cell death mode transition was specifically regulated by CypD. As we previously demonstrated, cellular CypD expression levels of mRNA and protein coincided with each other perfectly (11). We then measured the expression levels of CypD mRNA after HNK exposure in MCF-7 cells using RT-PCR. CypD mRNA levels in MCF-7 cells after HNK exposure was evaluated in all groups with different incubation durations (Fig. 4A and B). CypD mRNA levels increased with the extension of incubating time in the early death phase and declined in the late-phase $(6 \mathrm{~h})$. A possible explanation for the declined CypD mRNA levels in late-phase is that cells are under cellular collapse. Fig. 4B provides details of CypD mRNA levels between groups at different doses of incubation. CypD mRNA levels manifested a gradually increasing tendency with the extension of doses (Fig. 4B) $(\mathrm{P}<0.001)$. CypD mRNA level was suppressed in apoptosis-predominant group (HNK $20 \mu \mathrm{g}$ / $\mathrm{ml})$, was parallel in apoptosis and necrosis-balanced group (HNK $25 \mu \mathrm{g} / \mathrm{ml}$ ), whereas elevated in necrosis-predominant group (HNK 30 and $40 \mu \mathrm{g} / \mathrm{ml}$ ) (Fig. 4B). These results indi- 


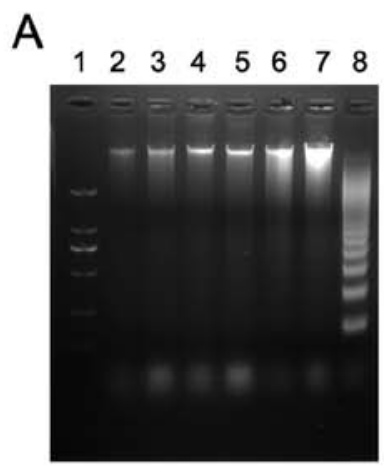

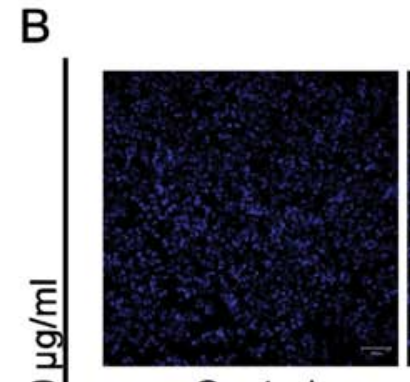

Control

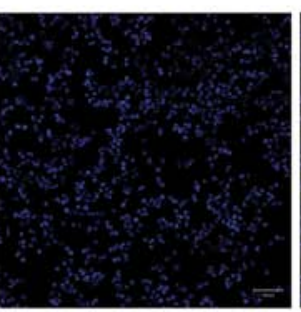

$2 \mathrm{~h}$

D

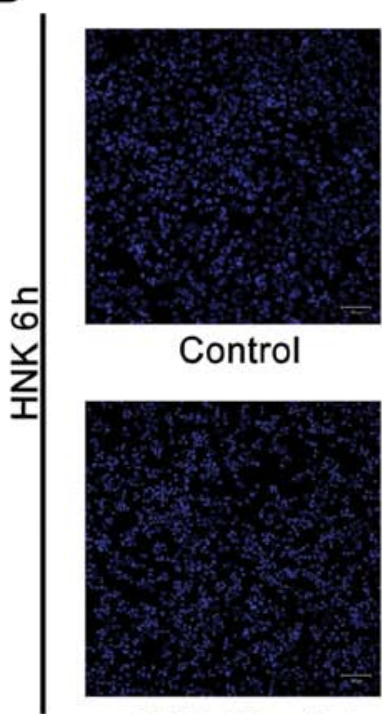

HNK $25 \mu \mathrm{g} / \mathrm{ml}$

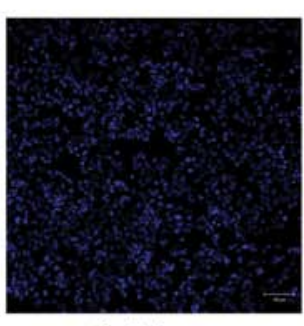

$0.5 \mathrm{~h}$

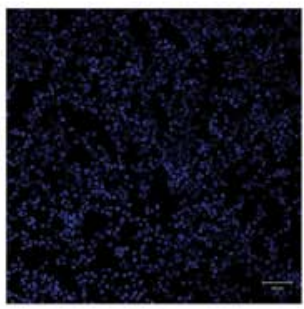

$4 \mathrm{~h}$

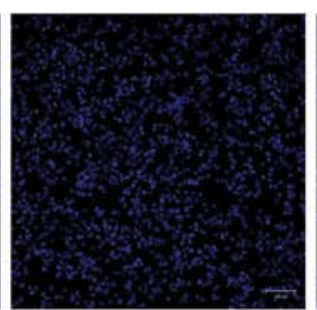

$\mathrm{HNK} 15 \mu \mathrm{g} / \mathrm{ml}$

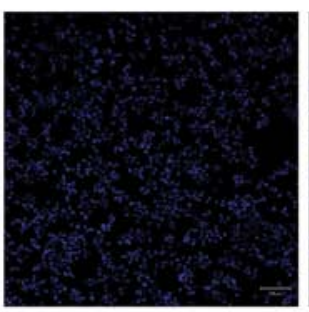

$\mathrm{HNK} 30 \mu \mathrm{g} / \mathrm{ml}$

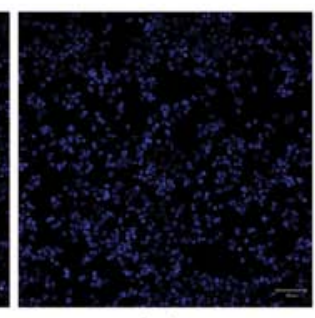

$1 \mathrm{~h}$

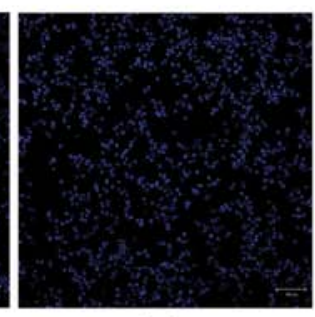

$6 \mathrm{~h}$

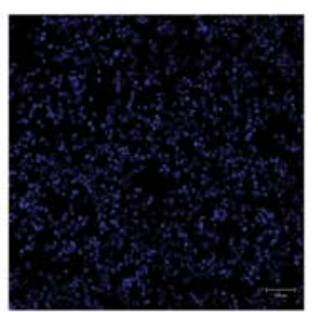

$\mathrm{HNK} 20 \mu \mathrm{g} / \mathrm{ml}$

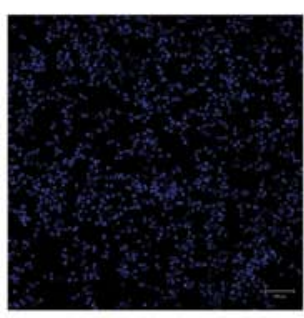

$\mathrm{HNK} 40 \mu \mathrm{g} / \mathrm{ml}$

Figure 3. No marked manifestation of late-stage apoptosis was detected by Hoechst 33342 staining and DNA laddering. There were no obvious DNA ladder patterns in all treatment groups after both (A) time-gradient and (C) dose-gradient treatments with HNK. Simultaneously, no chromatin condensation (apoptotic bodies) was detected in any treatment groups after (B) time-gradient or (D) dose-gradient treatments with HNK. Nos. 1 to 8 marked in (A) stands for DNA marker; control; HNK $40 \mu \mathrm{g} / \mathrm{ml}$ treatments for $0.5,1,2,4$ and $6 \mathrm{~h}$ in MCF-7 cells; and HL-60 cells treated with VP-16 for $6 \mathrm{~h}$, respectively. Nos. 1 to 8 marked in (B) stands for DNA marker; control; HNK 15, 20, 25, 30 and $40 \mu \mathrm{g} / \mathrm{ml}$ treatments for $6 \mathrm{~h}$ in MCF-7 cells; and HL-60 cells treated with VP-16 for $6 \mathrm{~h}$, respectively. In DNA ladder detection, HL-60 cells treated with VP-16 for $6 \mathrm{~h}$ were introduced as a positive control.

cated CypD was a potential modulator of HNK-triggered cell death mode transition time- and dose-dependently.

Cyclosporin A (CsA) targets and binds to the mitochondria CypD, which subsequently inhibites modulated-function of CyPD in cell death (17). We found CsA dramatically inhibited HNK induced cell death using MTT assay (Fig. 4C) at doses of 15 and $25 \mu \mathrm{M}$. Further, we used AV/PI staining methods to determine whether HNK induced time-dependent necrotic cell death was inhibited by CsA. We increased total dose (through increasing volume of drug, $2 \mathrm{ml} /$ well) in each well with a similar concentration of HNK $(40 \mu \mathrm{g} / \mathrm{ml})$ in order to amplify its necrotic death induction effects. Pretreatment with $15 \mu \mathrm{M}$ CsA for $2 \mathrm{~h}$ significantly inhibited HNK-induced necrotic cell death (PI staining-positive cells) with HNK incubation of 2, 4 and $6 \mathrm{~h}$, respectively $(\mathrm{P}<0.001)$ (Fig. 4D). The evidence supports CypD was a potential modulator of HNK-triggered cell death mode transition.

RIP3 expression correlates with HNK-induced cell death switch from apoptosis to programmed necrosis. Programmed necrosis is defined as necrosis highly regulated by RIP1 and RIP3 (2). RIP3 is essential and crucial component in the initiation of programmed necrosis $(18,19)$, but has no role in apoptosis $(20,21)$. Enhanced expression of RIP3 is strongly associated with increased programmed necrosis (2) and enable the switch of TNF-induced cell death from apoptosis to necrosis (20). We 

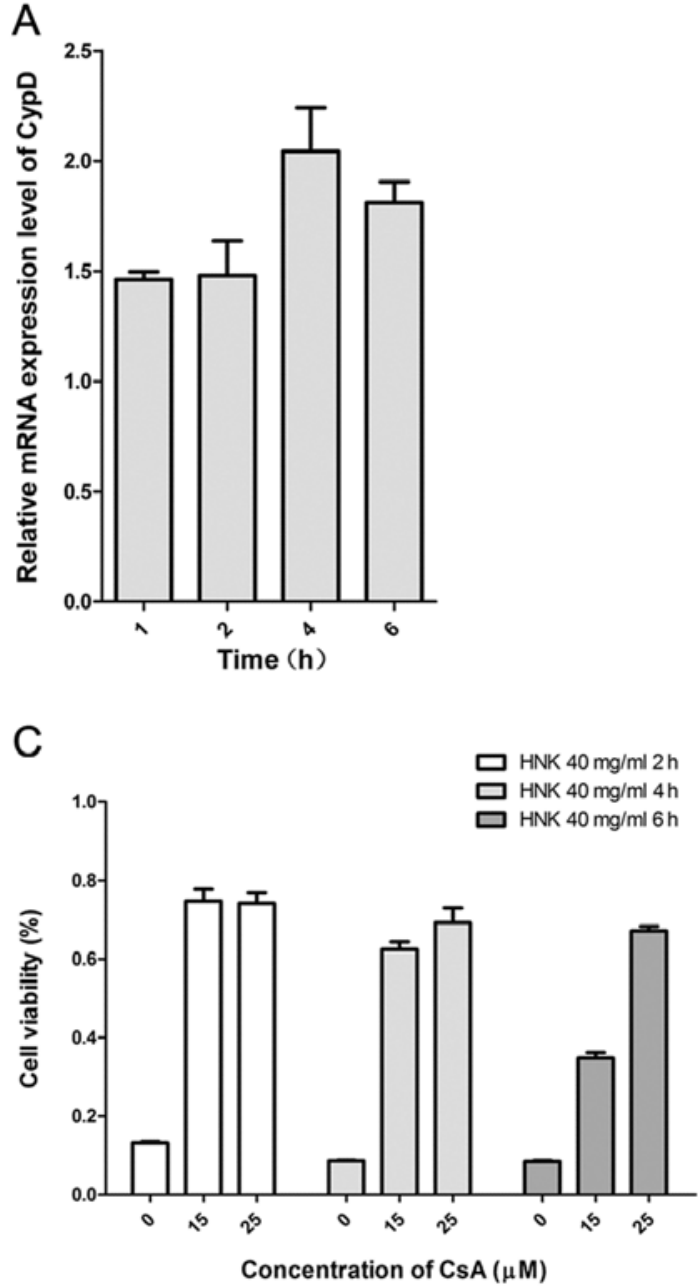

B
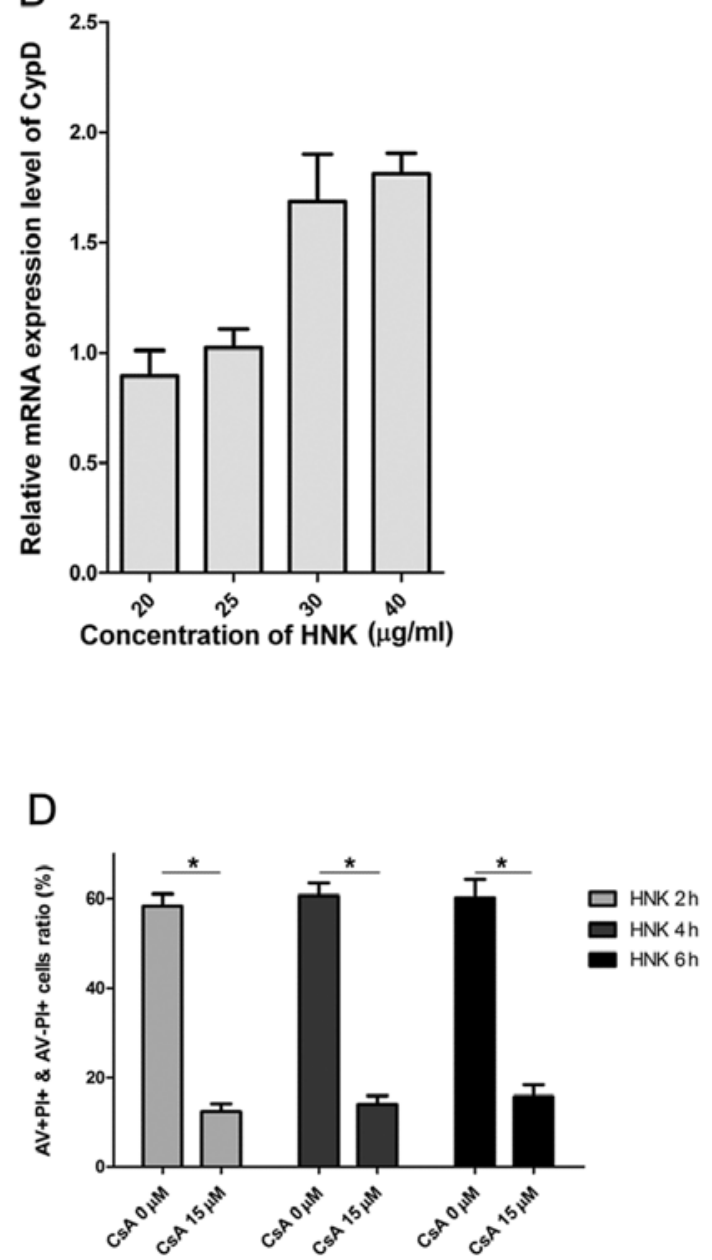

Figure 4. Cyclophilin D (CypD) is a vital modulator in HNK-induced apoptosis to programmed necrotic cell death transition. (A) Expression of CypD mRNA increased in all time-gradient treatment-groups. (B) CypD mRNA expressions gradually increased in parallel with dose-gradients. (C) Both 15 and $25 \mu \mathrm{M}$ cyclosporin A (CsA) significantly blocked time-gradient HNK-induced cells death. CsA pretreatment (15 $\mu \mathrm{M})$ dramatically inhibited HNK (40 $\mu \mathrm{g} / \mathrm{ml}$ incubation for 2,4 and $6 \mathrm{~h}$, respectively) induced necrotic cell death (PI staining positive cells). (D) P<0.001. Results are representative of three independent experiments. The values shown are the mean \pm SD.

further assessed RIP3 expression during HNK-triggered cell death mode transition using western blot analysis. Untreated MCF-7 did not express any detectable RIP3, which accords with a previous report (21). Expressions of RIP3 increased significantly after HNK treatment in a dose- and time-dependent manner $(\mathrm{P}<0.0001)$ (Fig. 5A, B, D and F). Furthermore, in programmed necrosis predominant groups, RIP3 expressions were approximate or more than 2 times compared with early-apoptosis predominant groups (HNK $25 \mu \mathrm{g} / \mathrm{ml}$ for $6 \mathrm{~h}$ or HNK $40 \mu \mathrm{g} / \mathrm{ml}$ for $1 \mathrm{~h}$ ) (Fig. 5A, B, D and F).

RIP1 is a critical switch in regulation cell fate, including $\mathrm{NF}-\kappa \mathrm{B}$ activation associated cell survival and proliferation, apoptosis and programmed necrosis (22-24). Under caspase-inhibited condition, RIP1 and RIP3 form a so-called 'necrosome' complex to initiate programmed necrosis signaling pathway (20). We further assessed RIP1 expression during HNK treatment using western blot analysis. Results indicated MCF-7 cells expressed reduced-RIP1 in all treatment groups compared with baseline level of normal MCF-7 cells (Figs. 5A, 6B). The RIP1 expression inhibition after
HNK treatments was dose- and time-dependent (Fig. 5E and $\mathrm{G})$.

We also detected, despite pretreatment with $15 \mu \mathrm{M}$ CsA for $2 \mathrm{~h}$ significantly inhibited HNK-induced necrotic cell death, it did not affect enhanced RIP3 expression triggered by HNK (Fig. 5C). Overall, these results specifically revealed RIP3 was a potential regulator in HNK-induced programmed necrosis and cell mode transition from apoptosis to programmed necrosis.

HNK induces PTEN overexpression paralleling with cell death mode transition. $\mathrm{Bcl}-2$ and $\mathrm{Bcl}-\mathrm{xl}$ are pro-survival proteins of the Bcl-2 family. They excert anti-apoptotic effect through sequestering and inhibiting pro-apoptotic Bcl-2 proteins, which may trigger mitochondrial outer membrane permeabilization (25-27). Overexpression of these anti-apoptotic $\mathrm{Bcl}-2$ proteins protects cells from apoptosis induction from a broad range of apoptotic stimuli (26). We aimed to detect the relevance between HNK-triggered apoptosis to programmed necrotic cell death transition and expression of 
A

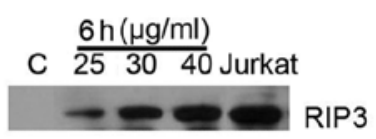

B

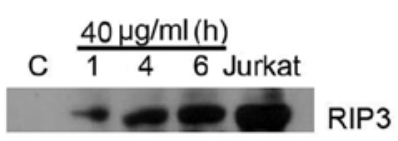

C

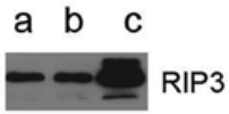

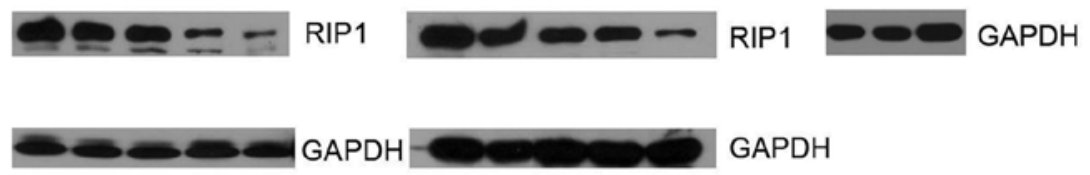
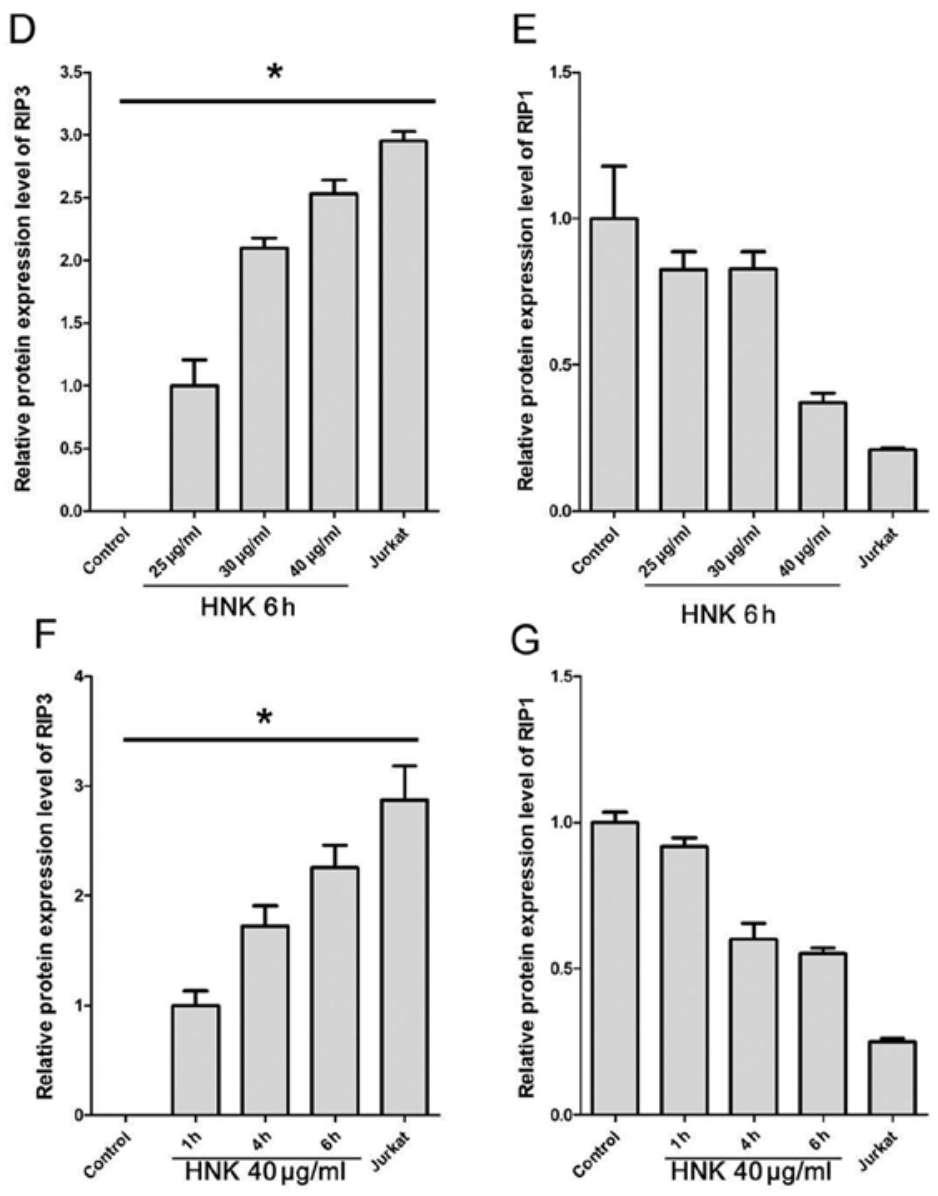

Figure 5. RIP3 expression correlates with transition of HNK-induced apoptosis to programmed necrotic cell death. (A, B and C) After incubation with HNK, cell protein expression levels were determined by western blot analysis. RIP3 expressions apparently increased parallelling with expanding of necrosis in (D) a dose-dependent and (F) time-dependent manner, whereas RIP1 expression decreased (E and G). (C) Blocking HNK-induced programmed necrosis with CsA did not notably affect enhanced RIP3 expression. (Ca and b) stand for MCF-7 cells treated with HNK $40 \mu \mathrm{g} / \mathrm{ml}$ for $6 \mathrm{~h}$ without or with $15 \mu \mathrm{M} \mathrm{CsA}$ pretreatment, (Cc) indicates Jurkat cells. Protein expressions of Jurkat cells were introduced as positive control during western blot analysis. (D-G) Relative protein expression was determined compared with that of MCF-7 cells treated (D) with HNK $25 \mu \mathrm{g} / \mathrm{ml}$ for $6 \mathrm{~h}$, (F) with HNK $40 \mu \mathrm{g} / \mathrm{ml}$ for $1 \mathrm{~h}$ and (E and G) without HNK treatment, respectively, after adjusting with corresponding GAPDH expression. One-way analysis of variance (ANOVA) was used for evaluation of time- and dose-response curves. Results are representative of three independent experiments. The values shown are the mean \pm SD.

Bcl-2 and Bcl-xl. No obvious changes in expressions of Bcl-2 and Bcl-xl proteins were detected paralleling with increased doses or treatment durations using western blot analysis (Fig. 6A and B).

Loss of expression or inactivation of PTEN amplifies the PI3K-Akt-mTOR pathway, which promotes cell survival and proliferation (28-30). PTEN protein expression during cell death mode transition triggered by increased doses or dura- tion of incubation was also determined. Western blot analysis results revealed that PTEN protein expressions increased paralleling with HNK incubated-duration (Fig. 6A) and apparently enhanced in necrosis-predominant group (HNK $40 \mu \mathrm{g} / \mathrm{ml}$ for 2, 4 and $6 \mathrm{~h}$ ). Similarly, intensive expression of PTEN was also detected with increased doses of HNK, especially in necrosis-predominant group (HNK 30 and $40 \mu \mathrm{g} / \mathrm{ml}$ for $6 \mathrm{~h}$ ) (Fig. 6B). 
A

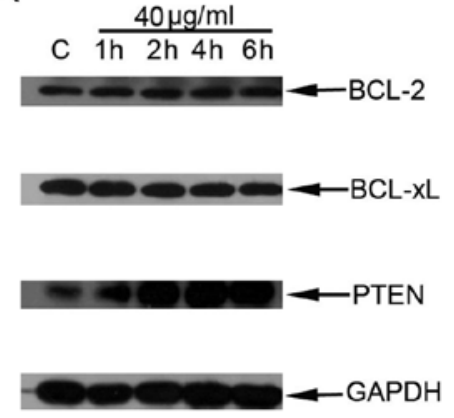

B

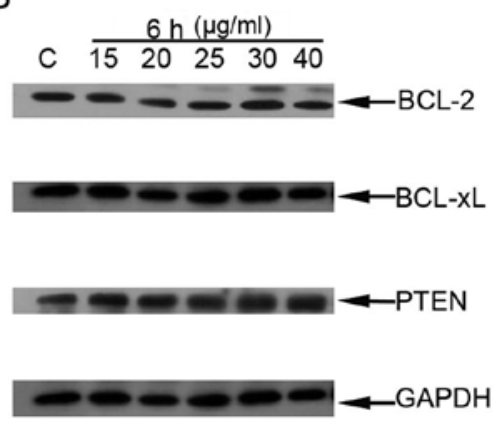

Figure 6. PTEN overexpression paralleling with cell death mode transition. Protein expression of Bcl-2, Bcl-xl, PTEN and GAPDH after (A) time- and (B) dosegradient treatments with HNK was determined with western blot analysis.

\section{Discussion}

Cell death is classified as extrinsic apoptosis, caspase-dependent or -independent intrinsic apoptosis, regulated necrosis, autophagic cell death and others by measurable biochemical features (1). Different from conventional concept, recent studies demonstrate necrosis can also proceed in a well-regulated manner, which is frequently defined as programmed necrosis. Current evidence indicates chemicals often trigger different cell death modes in a dose-dependent manner, including autophagy or apoptosis after lower-dose and necrosis at higher-dose exposure (13). We previously reported honokiol at higher doses induced programmed necrosis highly-regulated by cyclophilin D (CypD) in HL-60, MCF-7 and HEK293 cell lines (11), whereas other groups revealed HNK-induced apoptosis in such cell lines $(31,32)$. From this perspective, we supposed HNK could trigger programmed cell death switching from apoptosis to programmed necrosis in a dose- and time-dependent manner. Data from flow cytometric analysis indicated that a proportion of early-stage apoptosis $\left(\mathrm{AV}^{+} \mathrm{PI}\right)$ decreased and that of necrosis $\left(\mathrm{PI}^{+}\right)$increased with extension of treatment time at a fixed dose of HNK $(40 \mu \mathrm{g} / \mathrm{ml})$ in MCF-7 cells. Internucleosomal DNA fragmentation is one of the hallmarks of apoptosis at later stage (or degradation phase), which are simply detectable as a ladder pattern in electrophoresis of isolated DNA. Nuclear chromatin condensation and apoptotic bodies are both morphological characteristic manifestations of apoptosis and are detectable using nuclei staining by Hoechst 33342 . Hoechst 33342 staining, DNA laddering demonstrated that the increased $\mathrm{PI}^{+}$cells were not late-stage apoptosis as no obvious DNA ladder pattern or chromatin condensation (apoptotic bodies) were detected. These results reveal that with the extension of treatment time, HNK $40 \mu \mathrm{g} / \mathrm{ml}$ triggered early-stage apoptosis which did not switch to late-stage apoptosis but to programmed necrosis. Similar results were obtained with dose extension of HNK with a fixed treatment time $(6 \mathrm{~h})$. Such experimental results in the current study provide substantial evidence for the original assumptions and confirm HNK triggered cell death mode transition from earlystage apoptosis to programmed necrosis.

The most well-characterized form of programmed necrosis is 'necroptosis', which is triggered by TNF and dependent on the assembly of RIPhomotypicinteraction motif(RHIM)-dependent necrotic signaling complex of RIP1 and RIP3 $(3,21,22,33,34)$. Expression of RIP1 or RIP3 is frequently-used to determine the existence of programmed necrosis. In necroptosis, RIP1 is critical component in formation of necrotic complex 'necrosome'. RIP1 protein is frequently overexpressed in cells that have undergone necroptosis and couples with RIP3 forming a functional amyloid signaling complex required for necroptosis (22). Our results demonstrated RIP1 protein expression was downregulated in a dose- and time-dependent manner coupling with HNK triggered cell death mode transition. Consequently, these results indicate HNK-induced programmed necrosis and cell death mode transition are potentially RIP1-independent. Although distinct from necroptosis, it is still explainable that programmed necrosis can also proceed in the absence of RIP1 in some cell context triggered by certain stimuli, such as double-stranded DNA virus (murine cytomegalovirus, MCMV) and toxic stress (35-37). Different from RIP1, current evidence indicates RIP3 is indispensable for programmed necrosis and participates in constitution of all demonstrated necrotic complexes triggered by various stimuli (3). Data in the current study revealed protein expression of RIP3 was upregulated in a dose- and time-dependent manner parallelling with HNK-triggered cell death mode transition. These data provide additional evidence that HNK triggered programmed necrosis and cell death modes transition may initiate and be highly-regulated by RIP3. RIP3 can trigger programmed necrosis without RIP1. Besides RIP1, RIP3 may also either form a homotypic complex or interact with other cellular RHIMcontaining proteins (such as DNA-dependent activator of interferon regulatory factors, DAI) to form a necrotic complex and trigger a RIP1-independent necrosis $(3,33,38)$. We speculate HNK-triggered programmed necrosis and cell death modes transition maybe highly-regulated by RIP3 through assembly of a necrotic complex with some other proteins besides RIP1 and initiate programmed necrosis process. The definite signal pathway initiating the HNK-induced programmed necrosis still needs further evaluation.

Although current evidence associated with execution process of programmed necrosis is still unclear, a series of cellular events are revealed downstream of RIP1/RIP3-containing complex activation. These cellular events generally take place in mitochondria and include reactive oxygen species (ROS) over-production, cellular ATP depletion, enhance glycogenolysis, glycolysis and glutaminolysis. Mitochondrial permeability transition (mPT) is a crucial event in signaling network of cell death, which participates in 
regulation of both apoptosis and programmed necrosis. Recent evidence indicates cyclophilin $\mathrm{D}(\mathrm{CypD})$ is a vital protein involved in the mPT and acts as 'gatekeeper', which regulates some necrotic but not apoptotic cell death (14), and comports as apoptotic repressor $(15,16)$. We previously reported CypD is a critical regulator in HNK induced programmed necrotic cell death, downregulated CypD by Cyps inhibitor (CsA) and siRNAs can significantly suppress HNK-induced programmed necrosis (11). In the current study we revealed CypD modulated HNK-triggered cell death mode transition. CypD expression gradually increased in parallel with HNK-triggered cell death switch from early-stage apoptosis to programmed necrosis. Pretreatment with CsA observably increased cell viabilities and inhibited HNK-induced necrosis. These results indicate upregulated CypD expression may block the apoptosis process between early and late stage and trigger the switch from earlystage apoptosis to programmed necrosis in MCF-7 cells after HNK treatment.

Our results indicate CypD may act downtream of RIP3 as a pivotal modulator in execution process of programmed necrosis for the following reasons: i) RIP3 is essential and crucial component in the initiation of programmed necrosis, while mitochondrial events act downstream of the RIP1/RIP3-contained complex activation and take responsibility for execution of programmed necrosis; ii) cyclophilin D (CypD) is a vital protein involved in the $\mathrm{mPT}$ and regulate mitochondrial events; iii) our results indicated CsA blocked HNK triggered programmed necrosis but without influence on RIP3 expression.

$\mathrm{Bcl}-2$ and $\mathrm{Bcl}-\mathrm{xl}$ are anti-apoptotic proteins of Bcl-2 family. They inhibit pro-apoptotic Bcl-2 proteins to suppress their triggered mitochondrial outer membrane permeabilization and perform anti-apoptotic effects (25-27). Proteins of Bcl-2 family regulate programmed necrosis (3), which is evidenced as TNF-induced programmed necrosis may be restrained by Bcl-xl (39). We also assessed their expressions after time gradient and concentration gradient treatments of HNK. Results indicate HNK does not conspicuously affect Bcl-2 and Bcl-xl expressions. We have previously demonstrated overexpression of Bcl-2 and Bcl-xl did not apparently suppress HNK triggered necrosis (11). Based on this evidence, Bcl-2 and Bcl-xl do not participate in regulation of HNK triggered necrosis. On the other hand, these results are in variance with previous reports, which demonstrate $\mathrm{Bcl}-2$ and $\mathrm{Bcl}-\mathrm{xl}$ are frequently downregulated during $\mathrm{HNK}$-induced apoptosis in a series of tumor cell lines $(6,40-44)$. A possible explanation for this difference is that $\mathrm{Bcl}-2$ takes different roles in the process of apoptosis and necrosis. Besides, previously evidence demonstrates CypD may exert anti-apoptotic effect through interacting with Bcl-2 (16). Existence of interation between CypD and Bcl-2 (and other antiapoptotic proteins) in HNK-triggered cell death mode transition still needs further evaluation.

This study revealed that HNK has dramatic antitumor effects in breast cancer cell lines. It triggers cell death mode transition from early-stage apoptosis to programmed necrosis time- and dose-dependently. This programmed necrosis and death mode transition may be potentially RIP3-dependent. The death mode transition and execution process of programmed necrosis is highly regulated by cyclophilin $\mathrm{D}$.

\section{Acknowledgements}

The authors are thankful for the research grants from National Natural Science Foundation of China (no. 30901741) and the Department of Education of Zhejiang Province of China (no. Y201225802).

\section{References}

1. Galluzzi L, Vitale I, Abrams JM, et al: Molecular definitions of cell death subroutines: recommendations of the Nomenclature Committee on Cell Death 2012. Cell Death Differ 19: 107-120, 2012.

2. Vanlangenakker N, Vanden Berghe $\mathrm{T}$ and Vandenabeele P: Many stimuli pull the necrotic trigger, an overview. Cell Death Differ 19: 75-86, 2012.

3. Han J, Zhong CQ and Zhang DW: Programmed necrosis: backup to and competitor with apoptosis in the immune system. Nat Immunol 12: 1143-1149, 2011.

4. Tian W, Xu D and Deng YC: Honokiol, a multifunctional tumor cell death inducer. Pharmazie 67: 811-816, 2012.

5. Battle TE, Arbiser J and Frank DA: The natural product honokiol induces caspase-dependent apoptosis in B-cell chronic lymphocytic leukemia (B-CLL) cells. Blood 106: 690-697, 2005.

6. Park EJ, Min HY, Chung HJ, et al: Down-regulation of $\mathrm{c}-\mathrm{Src} / \mathrm{EGFR}$-mediated signaling activation is involved in the honokiol-induced cell cycle arrest and apoptosis in MDA-MB-231 human breast cancer cells. Cancer Lett 277: 133-140, 2009.

7. Raja SM, Chen S, Yue P, et al: The natural product honokiol preferentially inhibits cellular FLICE-inhibitory protein and augments death receptor-induced apoptosis. Mol Cancer Ther 7: 2212-2223, 2008

8. Shigemura K, Arbiser JL, Sun SY, et al: Honokiol, a natural plant product, inhibits the bone metastatic growth of human prostate cancer cells. Cancer 109: 1279-1289, 2007.

9. Chen YJ, Wu CL, Liu JF, et al: Honokiol induces cell apoptosis in human chondrosarcoma cells through mitochondrial dysfunction and endoplasmic reticulum stress. Cancer Lett 291: 20-30, 2010.

10. Mannal PW, Schneider J, Tangada A, McDonald D and McFadden DW: Honokiol produces anti-neoplastic effects on melanoma cells in vitro. J Surg Oncol 104: 260-264, 2011

11. Li L, Han W, Gu Y, et al: Honokiol induces a necrotic cell death through the mitochondrial permeability transition pore. Cancer Res 67: 4894-4903, 2007.

12. Xu D, Lu Q and Hu X: Down-regulation of P-glycoprotein expression in MDR breast cancer cell MCF-7/ADR by honokiol. Cancer Lett 243: 274-280, 2006.

13. Orrenius S, Nicotera P and Zhivotovsky B: Cell death mechanisms and their implications in toxicology. Toxicol Sci 119: 3-19, 2011.

14. Nakagawa T, Shimizu S, Watanabe T, et al: Cyclophilin D dependent mitochondrial permeability transition regulates some necrotic but not apoptotic cell death. Nature 434: 652-658, 2005.

15. Schubert A and Grimm S: Cyclophilin D, a component of the permeability transition-pore, is an apoptosis repressor. Cancer Res 64: 85-93, 2004.

16. Eliseev RA, Malecki J, Lester T, Zhang Y, Humphrey J and Gunter TE: Cyclophilin D interacts with Bcl2 and exerts an anti-apoptotic effect. J Biol Chem 284: 9692-9699, 2009.

17. Rasola A and Bernardi P: The mitochondrial permeability transition pore and its involvement in cell death and in disease pathogenesis. Apoptosis 12: 815-833, 2007.

18. Zhang DW, Zheng M, Zhao J, et al: Multiple death pathways in TNF-treated fibroblasts: RIP3- and RIP1-dependent and independent routes. Cell Res 21: 368-371, 2011.

19. Kreuzaler P and Watson CJ: Killing a cancer: what are the alternatives? Nat Rev Cancer 12: 411-424, 2012

20. Zhang DW, Shao J, Lin J, et al: RIP3, an energy metabolism regulator that switches TNF-induced cell death from apoptosis to necrosis. Science 325: 332-336, 2009.

21. He S, Wang L, Miao L, et al: Receptor interacting protein kinase-3 determines cellular necrotic response to TNF-alpha. Cell 137: 1100-1111, 2009. 
22. Li J, McQuade T, Siemer AB, et al: The RIP1/RIP3 necrosome forms a functional amyloid signaling complex required for programmed necrosis. Cell 150: 339-350, 2012.

23. Moquin D and Chan FK: The molecular regulation of programmed necrotic cell injury. Trends Biochem Sci 35: 434-441, 2010.

24. Declercq W, Vanden Berghe T and Vandenabeele P: RIP kinases at the crossroads of cell death and survival. Cell 138: 229-232, 2009.

25. Kurokawa $\mathrm{M}$ and Kornbluth S: Caspases and kinases in a death grip. Cell 138: 838-854, 2009.

26. Kelly PN and Strasser A: The role of Bcl-2 and its pro-survival relatives in tumourigenesis and cancer therapy. Cell Death Differ 18: 1414-1424, 2011.

27. Youle RJ and Strasser A: The BCL-2 protein family: opposing activities that mediate cell death. Nat Rev Mol Cell Biol 9: 47-59, 2008.

28. Song MS, Salmena L and Pandolfi PP: The functions and regulation of the PTEN tumour suppressor. Nat Rev Mol Cell Biol 13: 283-296, 2012.

29. Hanahan D and Weinberg RA: Hallmarks of cancer: the next generation. Cell 144: 646-674, 2011.

30. Martelli AM, Evangelisti C, Chappell W, et al: Targeting the translational apparatus to improve leukemia therapy: roles of the PI3K/PTEN/Akt/mTOR pathway. Leukemia 25: 1064-1079, 2011.

31. Wolf I, O'Kelly J, Wakimoto N, et al: Honokiol, a natural biphenyl, inhibits in vitro and in vivo growth of breast cancer through induction of apoptosis and cell cycle arrest. Int J Oncol 30: 1529-1537, 2007.

32. Liu H, Zang C, Emde A, et al: Anti-tumor effect of honokiol alone and in combination with other anti-cancer agents in breast cancer. Eur J Pharmacol 591: 43-51, 2008.

33. Mocarski ES, Upton JW and Kaiser WJ: Viral infection and the evolution of caspase 8-regulated apoptotic and necrotic death pathways. Nat Rev Immunol 12: 79-88, 2012.

34. Sun L, Wang H, Wang Z, et al: Mixed lineage kinase domainlike protein mediates necrosis signaling downstream of RIP3 kinase. Cell 148: 213-227, 2012.
35. Motani K, Kushiyama H, Imamura R, Kinoshita T, Nishiuchi T and Suda T: Caspase-1 protein induces apoptosis-associated speck-like protein containing a caspase recruitment domain (ASC)-mediated necrosis independently of its catalytic activity. J Biol Chem 286: 33963-33972, 2011.

36. Cho YS, Challa S, Moquin D, et al: Phosphorylation-driven assembly of the RIP1-RIP3 complex regulates programmed necrosis and virus-induced inflammation. Cell 137: 1112-1123, 2009.

37. Upton JW, Kaiser WJ and Mocarski ES: Virus inhibition of RIP3-dependent necrosis. Cell Host Microbe 7: 302-313, 2010.

38. Rebsamen M, Heinz LX, Meylan E, et al: DAI/ZBP1 recruits RIP1 and RIP3 through RIP homotypic interaction motifs to activate NF-kappaB. EMBO Rep 10: 916-922, 2009.

39. Ono K, Wang X, Kim SO, Armstrong LC, Bornstein P and Han J: Metaxin deficiency alters mitochondrial membrane permeability and leads to resistance to TNF-induced cell killing. Protein Cell 1: 161-173, 2010.

40. Jeong JJ, Lee JH, Chang KC and Kim HJ: Honokiol exerts an anticancer effect in T98G human glioblastoma cells through the induction of apoptosis and the regulation of adhesion molecules. Int J Oncol 41: 1358-1364, 2012.

41. Arora S, Bhardwaj A, Srivastava SK, et al: Honokiol arrests cell cycle, induces apoptosis, and potentiates the cytotoxic effect of gemcitabine in human pancreatic cancer cells. PLoS One 6: e21573, 2011.

42. Han LL, Xie LP, Li LH, Zhang XW, Zhang RQ and Wang HZ: Reactive oxygen species production and $\mathrm{Bax} / \mathrm{Bcl}-2$ regulation in honokiol-induced apoptosis in human hepatocellular carcinoma SMMC-7721 cells. Environ Toxicol Pharmacol 28: 97-103, 2009.

43. Deng J, Qian Y, Geng L, et al: Involvement of p38 mitogenactivated protein kinase pathway in honokiol-induced apoptosis in a human hepatoma cell line (hepG2). Liver Int 28: 1458-1464, 2008.

44. Hahm ER, Arlotti JA, Marynowski SW and Singh SV: Honokiol, a constituent of oriental medicinal herb Magnolia officinalis, inhibits growth of PC-3 xenografts in vivo in association with apoptosis induction. Clin Cancer Res 14: 1248-1257, 2008. 